\title{
Brief Report : Syndromes in Autistic Children in a Finnish Birth Cohort
}

\section{Timonen-Soivio, Laura}

2016-08

Timonen-Soivio , L , Vanhala , R, Malm , H, Hinkka-Yli-Salomaki , S , Gissler , M , Brown , A \& Sourander , A 2016 , ' Brief Report : Syndromes in Autistic Children in a Finnish Birth Cohort ' , Journal of Autism and Developmental Disorders , vol. 46 , no. 8 , pp. 2780-2784 . https://doi.org/10.1007/s

http://hdl.handle.net/10138/224089

https://doi.org/10.1007/s10803-016-2789-2

publishedVersion

Downloaded from Helda, University of Helsinki institutional repository.

This is an electronic reprint of the original article.

This reprint may differ from the original in pagination and typographic detail.

Please cite the original version. 


\title{
Brief Report: Syndromes in Autistic Children in a Finnish Birth Cohort
}

\author{
Laura Timonen-Soivio ${ }^{1,2} \cdot$ Raija Vanhala $^{2} \cdot$ Heli Malm ${ }^{1,3}$. \\ Susanna Hinkka-Yli-Salomäki ${ }^{1}$ - Mika Gissler ${ }^{1,5}$. \\ Alan Brown ${ }^{4,6} \cdot$ Andre Sourander ${ }^{1,4}$
}

Published online: 21 April 2016

(c) Springer Science+Business Media New York 2016

\begin{abstract}
We studied the association between specific congenital syndromes and autism spectrum disorders (ASD) in the large Finnish Register material. Our data include all children diagnosed with ASD $(n=4441)$ according to Finnish Hospital Discharge Register in 1987-2000. Four controls per each case were matched to sex, birthplace, date of birth ( \pm 30 days $)$ and residence in Finland $(n=17,695)$. The prevalence of specific congenital syndromes in the Finnish Register of Congenital Malformations was evaluated among the ASD group and the controls by sex. The results of this study suggest that there is an association between several etiologically different syndromes and ASD when compared to controls without ASD. Statistically significant associations were observed with 47,XYY, Sotos syndrome, neurofibromatosis I, and syndrome not otherwise specified. Syndromes were more common among males with ASD compared to controls. These results support the previous studies of etiological
\end{abstract}

Laura Timonen-Soivio

lamtim@utu.fi

1 Department of Child Psychiatry, University of Turku and Turku University Hospital, Lemminkäisenkatu 3/Teutori, 20014 Turku, Finland

2 Department of Child Neurology, Helsinki University Hospital, Helsinki, Finland

3 Teratology Information, Helsinki University Hospital, University of Helsinki, Helsinki, Finland

4 Department of Psychiatry, New York State Psychiatric Institute, College of Physicians and Surgeons, Columbia University, New York, NY, USA

5 National Institute for Health and Welfare, Helsinki, Finland

6 Department of Epidemiology, Columbia University, Mailman School of Public Health, New York, NY, USA heterogeneity of ASD and have importance in clinical examination, management and rehabilitation.

Keywords Syndromic autism - Chromosomal abnormalities - Autism spectrum disorder - Single gene disorders

\section{Introduction}

Syndromes are defined as a recognizable pattern of anomalies or dysfunctions which are known or thought to be etiologically and/or pathogenetically related (EUROCAT, OMIM). Causes include a single gene defect, a chromosomal anomaly or an environmental teratogen (EUROCAT) or unknown etiology. Many congenital syndromes have been associated with intellectual disability (ID) (Cohen et al. 2005; Benvenuto et al. 2009; Bhanumathi et al. 2009; Niklasson et al. 2009) and/or autism spectrum disorder (ASD) (Kielinen et al. 2004; Cohen et al. 2005; Benvenuto et al. 2009; Moss and Howlin 2009; Niklasson et al. 2009; Richards et al. 2015). Prenatal exposure to certain medications, such as valproate, has been associated with an autistic-like syndrome (Williams et al. 2001). Autistic traits in offspring have also been associated with toxins, such as with high alcohol consumption during pregnancy (Nanson 1992). The earlier population based register studies of the association between ASD and syndromes are few as the syndromes are rare. Kielinen et al. (2004) presented a population based study of 187 ASD children with one Klinefelter syndrome $(47, \mathrm{XXY})(0.5 \%)$, one $47, \mathrm{XYY}(0.5 \%)$, one Down syndrome $(0.5 \%)$, four Fragile-X-syndromes $(2.1 \%)$, two fetal alcoholic syndromes (1.1\%), one Sotos syndrome $(0.5 \%)$ and one tuberous sclerosis $(0.5 \%)$. The data on the 
study were derived from the hospital and institutional records of Northern Finland but with no comparison group. However, several genetic studies, case reports, reviews and studies examining the association between ASD and certain syndromes have been presented with varying methods and quality of data (Richards et al. 2015). The syndromes most often associated with ASD have been neurofibromatosis I (NFI), tuberous sclerosis and fragile-X syndrome (Bailey et al. 1998; Smalley 1998; Garg et al. 2013).

The purpose of this nationwide population based register study is to examine the association between ASD and congenital syndromes and to present the prevalence of ASD related syndromes by sex. We hypothesize that congenital syndromes and syndromes with congenital malformations are overrepresented among ASD children compared to controls based on the previous findings (Timonen-Soivio et al. 2015).

\section{Materials and Methods}

The Finnish Prenatal Study of Autism Spectrum Disorders (FIPS-A) is a case-control study based on the linkages of nationwide registries (Lampi et al. 2011). The present study includes the register data on children born in Finland between 1st of January 1987 and 31st of December 2000 $(\mathrm{n}=868,766)$. The children were followed for the diagnosis of ASD until 31st of December 2007 ( $n=4441)$. FIPS-A has been authorized by the Ministry of Social Affairs and Health and the National Institute for Health and Welfare (THL) in Finland. The ethics committees of the hospital district of Southwest Finland have given approval for the study.

The cases with ASD diagnoses were identified from the Finnish Hospital Discharge Register (FHDR). It includes the personal identity code (PIC) unique for every patient, dates of admission and discharge as well as the main diagnoses at discharge and up to three subsidiary diagnoses. The register was established in 1960 and maintained by THL. The inpatient diagnoses covering all hospitals in Finland are included in the register since 1967 and outpatient diagnoses since 1998. The FHDR covers all medical diagnoses collected from hospitals, health centres, military wards, prison and private hospitals. The diagnostic classification is based on the ICD-9 (1987-1995) and ICD-10 (1996-2007). The reliability and validity of FHDR register data has been shown to be good (Sund 2012). We included only the most recent autism diagnosis resulting in 19 cases who had a diagnosis based on ICD-9. The FHDR diagnoses of childhood autism have been validated (Lampi et al. 2010). The total number of children with ASD was 4441 (3540 boys and 901 girls), consisting of childhood autism ( $\mathrm{n}=1011$, mean age 5.8 years), Asperger syndrome
( $\mathrm{n}=1776$, mean age 9.7 years) and other PDD/PDD-unspecified $(\mathrm{n}=1654$, mean age 7.6 years). Parental ages and mother's socioeconomic status among cases and controls are presented in Table 1. The diagnoses of ASD in Finland are made in specialized clinics of child neurology or child and adolescent psychiatry, and are based on the ICD classification and criteria.

There were four matched controls to each case ( $n=17,695$ ) without meeting the criteria for ASD diagnoses. The controls were identified from Finnish Medical Birth Register (FMBR) established in 1987 and maintained by THL. The register includes the PIC for the mothers and the child, and data on pregnancy, pre- and neonatal period up to age of 7 days of all births in Finland. Cases and controls were matched by date of birth ( \pm 30 days), sex, place of birth by hospital and residence in Finland.

Information on syndromes was obtained from the Finnish Register of Congenital Malformations (FRCM) maintained by THL. The register was established in 1963 to monitor congenital anomalies in Finland. It collects data from hospitals, health care professionals, cytogenetic laboratories and draws data from other nationwide registers. The register contains data on congenital chromosomal and structural anomalies detected in stillborn and live born infants and fetuses as well as terminations of pregnancy due to congenital anomaly. The FRCM uses the ICD-coding system. The present study includes the ICD codes according to the Ninth Revision (ICD-9, 740-760, World Health Organization 1977). Syndromes were included when the total number in the FRCM was five or more among cases and controls together, based on ICD-9 and written text. The EUROCAT Syndrome Guide was also used.

Descriptive statistics on congenital syndromes are presented for ASD children and their matched controls. Frequencies were calculated separately for males and females. The associations between ASD and congenital syndromes were analyzed with stratified exact logistic regression suitable for a matched case-control design. Exact odds ratios

Table 1 The maternal socioeconomic status (SES) and parental mean ages among cases and controls

\begin{tabular}{|c|c|c|}
\hline & $\begin{array}{l}\text { Cases } \\
(\mathrm{n}=4441)\end{array}$ & $\begin{array}{l}\text { Controls } \\
(\mathrm{n}=17,695)\end{array}$ \\
\hline Maternal SES $^{\mathrm{a}}$ & $\mathrm{n}(\%)$ & $\mathrm{n}(\%)$ \\
\hline Upper white collar worker & $518(15.7)$ & $2124(16.0)$ \\
\hline Lower white collar worker & $1430(43.2)$ & $6055(45.7)$ \\
\hline Blue collar worker & $715(21.6)$ & $2769(20.9)$ \\
\hline Others & $647(19.6)$ & $2307(17.4)$ \\
\hline Mother's age(years), mean(SD) & $29.8(5.6)$ & $29.4(5.2)$ \\
\hline Father's age(years), mean $(\mathrm{SD})^{\mathrm{b}}$ & $32.3(6.4)$ & $31.9(5.9)$ \\
\hline
\end{tabular}

${ }^{a}$ Frequency missing $5571(25 \%)$

${ }^{\mathrm{b}}$ Missing (cases $\mathrm{n}=98$, controls $\mathrm{n}=208$ ) 
Table 2 Association between autism spectrum disorders (ASD) and congenital syndromes in cases and controls. Frequencies of males and females in congenital syndromes in autism spectrum disorders (ASD) and controls

\begin{tabular}{|c|c|c|c|c|}
\hline Syndromes & $\begin{array}{l}\text { ASD n }=4441 \\
\mathrm{n} \% \\
\text { Male n \% } \\
\text { Female n \% }\end{array}$ & $\begin{array}{l}\text { Controls } \mathrm{n}=17,695 \\
\mathrm{n} \% \\
\text { Male n \% } \\
\text { Female n \% }\end{array}$ & $\begin{array}{l}\text { Exact odd ratio and } \\
95 \% \text { confidence interval }\end{array}$ & $p$ value \\
\hline \multirow{2}{*}{$\begin{array}{l}\text { Klinefelter } \\
(47, X X Y)\end{array}$} & $4(0.1)$ & $4(0.03)$ & $4.0(0.7-21.5)$ & 0.1 \\
\hline & $\begin{array}{l}4(0.1) \\
-\end{array}$ & $\begin{array}{l}4(0.03) \\
-\end{array}$ & & \\
\hline 47,XYY & $\begin{array}{l}6(0.2) \\
6(0.2) \\
-\end{array}$ & $\begin{array}{l}4(0.03) \\
4(0.03) \\
-\end{array}$ & $6.0(1.4-28.9)$ & 0.01 \\
\hline Down & $\begin{array}{l}8(0.2) \\
7(0.2) \\
1(0.1)\end{array}$ & $\begin{array}{l}19(0.1) \\
15(0.1) \\
4(0.1)\end{array}$ & $1.7(0.6-4.0)$ & 0.31 \\
\hline 22q11.2 deletion syndrome & $\begin{array}{l}7(0.2) \\
6(0.2) \\
1(0.1)\end{array}$ & $\begin{array}{l}9(0.05) \\
8(0.06) \\
1(0.03)\end{array}$ & $3.1(0.9-9.4)$ & 0.05 \\
\hline Neurofibromatosis I & $\begin{array}{l}7(0.2) \\
6(0.2) \\
1(0.1)\end{array}$ & $\begin{array}{l}5(0.03) \\
4(0.03) \\
1(0.03)\end{array}$ & $5.6(1.5-22.4)$ & 0.01 \\
\hline Sotos & $\begin{array}{l}7(0.2) \\
6(0.2) \\
1(0.1)\end{array}$ & $\begin{array}{l}6(0.03) \\
5(0.04) \\
1(0.03)\end{array}$ & $4.7(1.3-16.8)$ & 0.01 \\
\hline Williams & $\begin{array}{l}3(0.07) \\
2(0.06) \\
1(0.1)\end{array}$ & $\begin{array}{l}2(0.01) \\
2(0.01) \\
0(0)\end{array}$ & $6.0(0.7-71.8)$ & 0.12 \\
\hline Valproate syndrome & $\begin{array}{l}3(0.07) \\
2(0.06) \\
1(0.1)\end{array}$ & $\begin{array}{l}2(0.01) \\
2(0.01) \\
0(0)\end{array}$ & $6.0(0.7-71.8)$ & 0.12 \\
\hline Fetal alcohol spectrum disorders & $\begin{array}{l}8(0.2) \\
7(0.2) \\
1(0.1)\end{array}$ & $\begin{array}{l}17(0.1) \\
13(0.1) \\
4(0.1)\end{array}$ & $1.9(0.7-4.6)$ & 0.22 \\
\hline Syndrome not otherwise specified & $\begin{array}{l}18(0.4) \\
16(0.5) \\
2(0.2)\end{array}$ & $\begin{array}{l}36(0.2) \\
27(0.2) \\
9(0.3)\end{array}$ & $2.0(1.1-3.6)$ & 0.03 \\
\hline
\end{tabular}

(OR) and their $95 \%$ confidence intervals $(\mathrm{CI})$ with exact $p$ values are presented. Statistical significance was judged at $p<0.05$. The statistical analyses were carried out using SAS statistical software (SAS 9.4; SAS Institute, Cary, NC, USA).

\section{Results}

All syndromes included were associated with ASD compared to controls (Table 2). The association was statistically significant for 47,XYY (OR 6.0, CI 1.4-28.9, $p=0.01$ ), NFI (OR 5.6, CI 1.5-22.4, $p=0.01$ ), Sotos syndrome (OR 4.7 , CI $1.3-16.8, p=0.01$ ) and syndrome not otherwise specified (NOS) (OR 2.0, CI 1.1-3.6, $p=0.03$ ). The sex distribution of syndromes in ASD and controls is presented in Table 2. Syndromes were overrepresented among males with ASD $(n=4441$, males $n=3540$, females $n=901)$ compared to controls. As the number of syndromes by sex is small, only frequencies are shown.

\section{Discussion}

The results of this study suggest that there is an association between several etiologically different syndromes and ASD when compared to controls without ASD. 47,XYY, Sotos 
syndrome, NF I and syndrome NOS have a statistically significant association with ASD. These results support the earlier findings of the strong association between ASD and presented syndromes (Ross et al. 2012; Garg et al. 2013; Sheth et al. 2015; Richards et al. 2015). In our study sample the number of syndromes previously associated with ASD including tuberous sclerosis (no cases, two controls) and fragile-X-syndrome (one case and two controls) were small. Second, males with ASD more often have syndromes compared to controls. The overall male preference in ASD has been well-known (MMWR surveillance 2014), and in our sample the male-female ratio in ASD is 4:1 (males 3540, females 901). Theories of diagnostic bias related to sex and exposure to prenatal androgens have been presented (Baron-Cohen et al. 2011) and the study of elevated fetal steroidogenic activity in later diagnosed ASD males was recently published (BaronCohen et al. 2015).

The syndromes presented in this study are heterogeneous, consisting of sex- and autosomal chromosomal abnormalities, single gene disorders, prenatally acquired teratogenic syndromes and syndromes of unknown etiology. Most syndromes in our data such as Down syndrome, Williams syndrome, 22q11.2 deletion syndrome, Sotos syndrome, valproate syndrome and FASD, include dysmorphic features indicating early developmental and neurodevelopmental injury during prenatal life. Chromosomal abnormalities and single gene defects may cause disruption of neural connections, brain growth and synaptic morphology and different neurotoxins may cause loss of neurons and altered neurotransmission (Benvenuto et al. 2009).

The strengths of our study are the large sample size and the good coverage of the health registers on Finnish children. One limitation is that the association between ID, ASD and syndromes can not be presented. However, it is not possible to give reliable data on ID, because the diagnosis of ID is often given later, outside our study period. Also, usually a child with developmental delay is carefully examined. If a specific genetic or other syndrome is found and the syndrome implicitly includes ID as part of the phenotype, the separate ID diagnosis is not added. Thus the diagnosis of ID may be lacking in the register data when a syndrome is present. Other limitation is that some children in the FRCM might not have been diagnosed by the new cytogenetic techniques or an unknown diagnosis has been given (syndrome NOS). In addition all the children diagnosed earlier as Asperger syndrome are not necessarily genetically tested at all or type of testing varies depending on the medical unit, dysmorphic features of the child and family history. In the general population Klinefelter (47,XXY), 47,XYY and FASD might not be diagnosed if the behavioral features or characteristics are mild. However, the specific syndromes presented in this study have been well-known and appropriately diagnosed during our study period. The results might also be influenced by the fact that children diagnosed with ASD may be more carefully evaluated for these syndromes compared to controls.

We have shown that ASD is associated with several etiologically different syndromes. The syndromes with dysmorphic features are overrepresented in ASD compared to controls. In addition, syndromes are more common among males with ASD compared to controls. These results have importance in the clinical examination and management of ASD individuals. The results also provide evidence for a prenatal origin and a heterogeneous etiology of ASD.

Acknowledgments This study was supported by Grants from Sigrid Juselius Foundation, Finland (A. Sourander), Jane and Aatos Erkko Foundation, Finland (A. Sourander), National Institute of Environmental Health Sciences (R01 ES 019004), USA (A. Brown), National Institute of Mental Health (KO2 MH 65422), USA (A. Brown), Arvo Ylppö Foundation, Finland (L. Timonen-Soivio).

Author Contributions Laura Timonen-Soivio (LTS) participated in the study design, coordination, drafting and being as a corresponding author, Raija Vanhala (RV) participated in interpreting the data, drafting and revising the manuscript, Heli Malm (HM) was involved in the drafting and revising the manuscript, Mika Gissler (MG) was involved in drafting and revising the manuscript, Susanna Hinkka-Yli-Salomäki (SHYS) performed the statistical analysis and participated in the revision of manuscript, Alan Brown (AS) was involved in revising the manuscript and Andre Sourander (AS) participated in the study design, coordination, drafting and revising the manuscript. All authors read and approved the manuscript.

Funding None of the funding sources played a role in the conduct of the research.

\section{Compliance with Ethical Standards}

Conflict of interest The authors declare that they have no conflict of interest.

Ethical Approval This article does not contain any studies with human participants or animals performed by any of the authors.

\section{References}

Bailey, D. B, Jr, Mesibov, G. B., Hatton, D. D., Clark, D. D., \& Roberts, J. E. (1998). Autistic behavior in young boys with fragile X syndrome. Journal of Autism and Developmental Disorders, 28(6), 499-508.

Baron-Cohen, S., Auyeung, B., Norgaard-Pedersen, B., Hougaard, D. M., Abdallah, M. W., Megaard, L., et al. (2015). Elevated fetal steroidogenic activity in autism. Molecular Psychiatry, 20(3), 369-376.

Baron-Cohen, S., Lombardo, M. V., Auyeung, B., Ashwin, E., Chakrabarti, B., \& Kinickmeyer, R. (2011). Why are autism spectrum condititions more prevalent in males? PLoS Biology, 9(6), e1001081.

Benvenuto, A., Moavero, R., Alessandrelli, R., Manzi, B., \& Curatulo, P. (2009). Syndromic autism: Causes and pathogenetic pathways. World Journal of Pediatrics, 5(3), 169-176. 
Bhanumathi, B., Chetna, V. B., \& Neelan, A. G. (2009). Genetic studies in children with intellectual disability and autistic spectrum of disorders. Indian Journal of Human Genetics, 15(3), 103-107.

Cohen, D., Pichard, N., Torjuan, S., Baumann, C., Burglen, L., \& Excoffier, E. (2005). Spesific genetic disorders and autism: Clinical contribution towards their identification. Journal of Autism and Developmental Disorders, 35(1), 103-116.

EUROCAT_European surveillance of congenital anomalies. Collaboration Centre for the surveillance of Congenital anomalies. www.eurocat-network.eu.

Garg, S., Green, J., Leadbitter, K., Emsley, R., Lehtonen, A., Evans, D. G., et al. (2013). Neurofibromatosis type I and autism spectrum disorder. Pediatrics, 132(6), e1642-e1648.

Kielinen, M., Rantala, H., Timonen, E., Linna, S.-L., \& Moilanen, I. (2004). Associated medical disorders and disabilities in children with autistic disorder. Autism, 8(1), 49-60.

Lampi, K. M., Banerjee, P. N., Gissler, M., Hinkka-Yli-Salomäki, S., Huttunen, J., \& Kulmala, U. (2011). Finnish prenatal study of autism and autism spectrum disorders: Overview and design. Journal of Autism and Developmental Disorders, 41(8), 1090-1096.

Lampi, K., Sourander, A., \& Gissler, M. (2010). Brief report: Validity of Finnish Registry based diagnoses of autism with the ADI-R. Acta Pediatrics, 99(9), 1425-1428.

MMWR surveillance. (2014). Prevalence of autism spectrum disorders among children aged 8 years-autism and developmental disabilities monitoring network 11 sites, USA 2010. Centre for Disease Control and Prevention (CDC), 63(2), 1-21.

Moss, J., \& Howlin, P. (2009). Autism spectrum disorders in genetic syndromes: Implications for diagnosis, intervention and understanding the wider autism spectrum disorder population. Journal of Intellectual Disability Research, 53(10), 852-873.
Nanson, J. (1992). Autism in fetal alcohol syndrome: A report of six cases. Alcohol Clinical Experimental Research, 16, 558-565.

Niklasson, L., Rasmussen, P., Oskardottir, S., \& Gillberg, C. (2009). Autism, ADHD, mental retardation and behavioral problems in 100 individuals with 22q11 deletion syndrome. Research of Developmental Disabilities, 30(4), 763-773.

OMIM-Online Mendelian Inheritance in Man. www.omim.org.

Richards, C., Jones, C., Groves, L., Moss, J., \& Oliver, C. (2015). Prevalence of autism spectrum disorder phenomenology in genetic disorders: A systematic review and meta-analysis. Lancet Psychiatry, 2(10), 909-916.

Ross, J. L., Roeltgen, D. P., Kushner, H., \& Zinn, A. R. (2012). Behavioral and social phenotypes in boys with $47, \mathrm{XYY}$ or Klinefelter 47,XXY. Pediatrics, 129(4), 769-778.

Sheth, K., Moss, J., Hyland, S., Stinton, C., Cole, T., \& Oliver, C. (2015). The behavioral characteristics of Sotos syndrome. American Journal of Medical Genetics Part A, 167(12), 2945-2956.

Smalley, S. L. (1998). Autism and tuberous sclerosis. Journal of Autism and Developmental Disorders, 28(5), 407-414.

Sund, R. (2012). Quality of the Finnish Hospital Discharge Register: A systematic review. Scandinavian Journal of Public Health, 40(6), 505-515.

Timonen-Soivio, L., Vanhala, R., Malm, H., Gissler, M., Hinkka-YliSalomäki, S., \& Leivonen, S. (2015). The association of congenital anomalies and autism spectrum disorders in a Finnish Birth Cohort. Developmental Medicine and Child Neurology, 57(1), 75-80.

Williams, G., King, J., Cunningham, M., Stephen, M., Kerr, B., \& Hersh, J. H. (2001). Fetal valproate syndrome and autism: Additional evidence of association. Developmental Medicine and Child Neurology, 43(3), 202-206.

World Health Organization (WHO). (1977). International Classification of Diseases, Ninth Revision (ICD-9). Geneva, Switzerland. 